\title{
The ethics of research related to health care in developing countries
}

\author{
J R McMillan, C Conlon
}

\begin{abstract}
A report by the Nuffield Council on Bioethics, contrary to the Declaration of Helsinki, permits most important research initiatives in developing countries.
\end{abstract}

$\mathrm{T}$ he Nuffield Council on Bioethics published its report The Ethics of Research Related to Health Care in Developing Countries ${ }^{1}$ on April 24th 2002. The report makes a number of recommendations on key issues in developing world research.

On the standard of care for developing world research the report says:

\begin{abstract}
"Wherever appropriate, participants in the control group should be offered a universal standard of care for the disease being studied. Where it is not appropriate to offer a universal standard of care, the minimum standard of care that should be offered to the control group is the best intervention available for that disease as part of the national public health system" (para 7.29).
\end{abstract}

On the issue of participant access to study interventions post research they say:

\begin{abstract}
"researchers should endeavour before the initiation of a trial to secure post-trial access for effective interventions for participants in the trial and that the lack of such arrangements should have to be justified to a research ethics committee" (para 9.31).
\end{abstract}

For research that is to be conducted in a developing country but is funded by body in a different country the report says:

We recommend that externally sponsored research projects should be subject to independent ethical review in the sponsors' country(ies) in addition to the country(ies) in which the research is to be conducted (para 8.22).

To help ensure that research conducted in a developing world country meets the research needs of that country the report says:

All countries should set priorities for research into health care (para 2.31) and when research funded by external sponsors is proposed which falls outside

\section{Abstract}

The Ethics of Research Related to Health Care in Developing Countries by the Nuffield Council on Bioethics makes a number of innovative recommendations that depart from codes such as the Declaration of Helsinki. It recommends that standards of care might be relativised to the standard of that nation. It recommends that very good reasons need to be given for not giving post-trial access to medications but recognises that there may be justifiable instances of this. It is the view of the authors that these and other recommendations of the report are sensible pieces of advice given the complexities of the developing world.

the national priorities for research into health care set by a host country, those proposing the research [should] be required to justify the choice of the research topic to the appropriate research ethics committees in both the host and sponsoring countries (para 3.32).

There is no shortage of general research guidelines but there is frustratingly little help for thinking through the complexities of developing world research. Given the need for guidance in this area the report is very timely, but the significant question is: does it give useful practical guidance on the ethics of developing world research? Our view is that it does.

This report represents a refreshing approach in that it provides useful practical guidance that results from knowledge, and careful analysis, of the challenges facing developing world research. Furthermore it provides a thoughtful assessment of most of the difficult questions that have been debated in the literature. In particular it addresses the problems of differing standards of care in different settings, the applicability and availability of the benefits of research, and the relationship between sponsoring countries and the countries where the research takes place.

\section{STANDARDS OF CARE}

One of the most important sections in the report is its discussion of standards of care for research in the developing world. The report was written after a number of papers had been published on this issue in the New England Journal

of Medicine, ${ }^{2}{ }^{3}$ and the report makes a significant contribution to the debate. This debate springs from one of the more controversial and prescriptive principles of the Declaration of Helsinki. Principle 29 of the declaration says:

\begin{abstract}
"The benefits, risks, burdens, and effectiveness of a new method should be tested against those of the best current prophylactic, diagnostic, and therapeutic methods. This does not exclude the use of placebo, or no treatment, in studies where no proven prophylactic, diagnostic or therapeutic method exists." 4
\end{abstract}

The difficulty is to know how the Helsinki requirement that research participants in the control arm of a study be assured of the best current prophylactic, diagnostic, and therapeutic methods in the context of the developing world. Lurie and Wolfe were highly critical of 15 studies conducted in the Côte d'Ivoire, Uganda, Tanzania, South Africa, Malawi, Thailand, Ethiopia, Burkina Faso, Zimbabwe, Kenya, and the Dominican Republic. These studies concerned the effectiveness of the antiretroviral drug zidovudine in the prevention of HIV transmission during pregnancy. The 15 studies involved randomising the antiretroviral drug, which had been shown in US studies to be effective in patients in the West, against a placebo.

Angell insists that the standards that are applied to research conducted in the developing world should be the same as 
those of the developed world. ${ }^{5}$ Thus, because it would have been unacceptable to randomise zidovudine against placebo in the US it should likewise be unacceptable in the developing world. Researchers and those responsible for reviewing developing world research have been placed in a difficult situation by this strong statement. While it might preferable always to have the same standard across the world, sticking strictly to this principle would stop a significant amount of important research. In such cases people have tended to "relativise" the standard of care to what is usually available in a developing country, or for that matter Britain or a country that has different standards from those of the US. Given that this appears to fly in the face of strongly worded advice from an editor of the New England Journal of Medicine, attempts to resolve this difficulty are important. ${ }^{5}$

One of the best things about the Nuffield report is that it provides sensible, well reasoned advice on standards of care. The report's recommendation that participants in a control group should be offered a universal stand of care unless there are good reasons why they shouldn't suggests that there is a prima facie duty to act in the way that Angell and Lurie and Wolfe suggest. The report's acknowledgement that there may be research where "it is not appropriate to offer a universal standard of care" and its suggestion that in such cases "the minimum standard of care that should be offered to the control group is the best intervention available for that disease as part of the national public health system" recognises that there is a need for some flexibility on this issue.

Clearly a great deal is riding on the qualifier not appropriate and the way this is worded is very close to a tautology. After all, how could the supporters of a universal standard of care insist upon a universal standard when it is not appropriate! The report suggests a number of conditions that would make a less than universal standard inappropriate. They give as an example the treatment of schistosomiasis with praziquantel and suggest that a less than universal standard would be inappropriate because "... an effective proven treatment for schistosomiasis exists and has been approved and implemented in affected countries around the world. The treatment has been demonstrated to be affordable and feasible to deliver, in a sustained manner in six developing countries" (Nuffield Council on Bioethics, ${ }^{1}$ p 92.) This example is uncontroversial and research that attempted to provide a lower standard of care would be highly dubious. The more contestable examples in the report concern research which offers a less than universal standard of care when there exists broad international agreement about what the best treatment for this condition is. They discuss the Côte d'Ivoire research into the prevention of perinatal transmission of HIV and note that the standard therapeutic regime for this condition is complex and requires a significant amount of medical infrastructure.

This complicated regimen, which requires voluntary counselling and testing for HIV to be performed early in pregnancy, has limited application for many developing countries where women have poor access to antenatal care and may only seek assistance from health care workers after the onset of labour (Nuffield Council on Bioethics, ${ }^{1}$ para 7.21 ).

They suggest that even though a universal standard of care cannot be provided to participants this research should still be conducted because it might help to develop responses to health care needs in developing countries. While we agree with the report's view about this research it is worth considering whether the reasons they give are adequate and justifiable.

In response to Angell's insistence upon a universal standard the report says that justice does not always require us to treat all people exactly the same. This means that if there is a morally relevant reason, we might defensibly treat some people in different ways while continuing to treat them with equal concern and respect. While this seems a reasonable account of justice there is something a little odd about applying this line of thinking to the Côte d'Ivoire research. Even if we decide that this research is justified the material differences between this location and the West don't make it "fair" that these people get a lesser standard of care. The participants in this research would be better off if they received the same standard of care as in the West so it is "unfair" that they are deprived of this benefit simply by virtue of living in a poor country. What is so complicated about these cases is determining whether something extra could be done to ameliorate this discrepancy. Kant famously said "ought implies can", meaning that it is a precondition of a moral requirement that it can actually be performed. The difficulty with research such as this is being certain that nothing can be done to bring the level of care up to a universal standard. If it really were impossible then the report's insistence that this is not "unfair" is more plausible.
Another way of applying justice to research like this is to focus upon the greater injustice, that of failing to provide what benefit we can and working toward developing interventions that are feasible for the developing world even though this might mean that such research is unjust to the extent that it does not do all that is humanly possible to deal with inequity. Also, such research may be a sufficient stimulus to improve standards of care or to pave the way for interventions that may be feasible in the future.

Perhaps the most radical suggestion in the report is the idea that it might in exceptionable circumstances be acceptable to provide a lesser standard of care than the national standard for that country. The report gives as an example a country where there is a national programme for the treatment of sexually transmitted diseases (STDs) but where the programme is not widely implemented. Research which randomised available care in these regions of poor access against the new national programme could show how much more effective the new national programme is. The report justifies this type of research because of its great value in improving treatment for those not in the research. One crucial argument that they did not mention here is that those people in the control arm, receiving what treatment is available in that region, are not being deprived of treatment that they would other wise have received. This is crucial, for if we change the details of this research slightly so that it is conducted in a region where there is good access to the national programme on STDs and then ask the controls to have the suboptimal treatment that those in less fortunate areas have access to, then this research looks altogether more problematic. One additional rule that the report could have added is that dropping from a universal standard of care is only justified when those in the control arm do not get a lesser standard of care than they would other wise have received.

\section{CONTINUATION OF CARE}

Another crucial consideration is what should happen when research has shown a treatment to be effective. Once again the Declaration of Helsinki makes a strong recommendation on this point. Principle 30 states:

"At the conclusion of the study, every patient entered into the study should be assured of access to the best proven prophylactic, diagnostic and therapeutic methods identified by the study." 4 
Failing to follow this principle may not be bad when research takes place within systems like the UK National Health Service because there may often be a treatment that is efficacious that people can take instead of the study medication. In the developing world, however, there will very often be few other options for therapy than the treatment shown to be effective during research. The problem is that the Helsinki recommendation is strongly worded and if a treatment is for a chronic illness the cost of having to supply treatment to research participants on an indefinite basis may mean that valuable developing world research is not conducted. Another complication that the report mentions is that the provision of medicines or better health care is primarily the responsibility of national governments and sponsors of research are not in a position to make unilateral decisions about this at the start of a trial.

The report makes a number of suggestions about how this problem should be handled. It says that those who review the research should also focus upon what will happen once the research is over, pointing out that a new intervention proves to be effective then it should be offered to those in the control arm once the research is over. This principle will work nicely for vaccine trials and other research where there is no long term therapeutic intervention.

The report recommends that researchers should secure post trial access for participants or justify a failure to do so to a research ethics committee. While this is a significant weakening of the Helsinki position, it still suggests there is a strong imperative to do everything that can reasonably be done to ensure post trial access.

In effect the report says we should rely on research ethics committees to make the hard decisions about whether post research access is adequate-just like the hard decisions that will need to be made about standards of care that are less than universal. The research ethics committee may be no better placed than the research sponsors to make unilateral decisions about health care policy in other countries.

\section{HOST COUNTRY AND} SPONSORING COUNTRY REVIEW

Given that the report suggests that ethics committees should decide most of the tough moral questions it is important that there is guidance about how developing world research should be reviewed. The report suggests there are three key levels of assessment: the proposal's relevance to priorities within host countries, the scientific validity of the research, and its ethical acceptability. The report proceeds to give an in depth discussion of each of these levels. One of the more interesting parts of this section is the recommendation that externally sponsored research should be reviewed by an independent committee in the sponsor's country as well as in the country where the research is to be conducted.

This is an important recommendation because in the absence of either type of review there is a risk that research will not meet local needs, may be reviewed by a committee with a vested interest in the research, or fail to meet appropriate international standards. The UK has made moves towards providing this with the work of the ethics committee of the London School of Hygiene and Tropical Medical, The Liverpool School of Tropical Medicine ethical committee and the Oxford Tropical Medical Research Ethics Committee.

\section{GENETICS AND DEVELOPING WORLD RESEARCH}

A significant amount of literature was written about sample collection for genetic testing as part of the Human Genome Project. The Nuffield Council on Bioethics has written other reports on genetics and ethics and it may be that they feel they have delivered their advice on this issue. Genetic testing and sampling can, however, be very significant for some indigenous groups and the one surprise omission from this report is the absence of guidance on this subject. Many studies conducted in the UK will include a component that involves the collecting of DNA for further research purposes.

\section{CONCLUSION}

Rather than producing a set of principles that must be applied to developing world research the Nuffield Council on Bioethics has produced a document that gives useful recommendations on key points, gives a high quality analysis of the issues, and will function as a very useful resource for those involved in the review and design of research in the developing world. It provides a well reasoned alternative to the Declaration of Helsinki for examining research in countries with poor resources, which the declaration does not address. Without such an alternative, a literal view of the Declaration of Helsinki would effectively prevent most important research initiatives in developing countries.

J Med Ethics 2004;30:204-206.

doi: 10.1136/jme.2002.001263

...............

\section{Authors' affiliations}

J R McMillan, Department of History and Philosophy of Science, University of Cambridge, Cambridge, UK

C Conlon, Nuffield Department of Medicine, John Radcliffe Hospital, Oxford, UK

A report by the Nuffield Council on Bioethics, contrary to the Declaration of Helsinki, permits most important research initiatives in developing countries.

Correspondence to: J R McMillan, Department of History and Philosophy of Science and Cambridge Genetics Knowledge Park, University of Cambridge, Free School Lane, Cambridge CB2 3RH, UK; jm439@cam.ac.uk

\section{REFERENCES}

1 Nuffield Council on Bioethics. The ethics of research related to health care in developing countries. London: Nuffield Council on Bioethics, 2002

2 Angell MM. The ethics of clinical research in the Third World. N Engl J Med 1997;337:847-9.

3 Lurie $\mathbf{P}$, Wolfe SM. Unethical trials of interventions to reduce perinatal transmission of the human immunodeficiency virus in developing countries. N Engl J Med 1997;337:853-6.

4 World Medical Association. Declaration of Helsinki, Edinburgh 2000. Edinburgh: Fifty second WMA General Assembly, 2000.

5 Angell MM. Investigators' responsibilities for human subjects in developing countries. N Engl J Med 2000;342:967-9. 